\title{
CONSOLIDANDO A RELEVÂNCIA DAS CULTURAS DAS COMUNIDADES EM PROJETOS DE INTERVENÇÃO: O TERRITÓRIO DA COMUNIDADE CAIÇARA DA PRAIA DO SONO
}

\author{
CONSOLIDATING THE RELEVANCE OF COMMUNITY CULTURES IN INTERVENTION \\ PROJECTS: THE TERRITORY OF THE CAIÇARA COMMUNITY OF PRAIA DO SONO
}

Gustavo MACHADO ${ }^{1}$, Tania MACIEL ${ }^{2}$, Carine Morrot de OLIVEIRA ${ }^{3}$, Michel THIOLLENT4

Palavras-chave: Ecologia social, Pesquisa qualitativa, Tecnologia social, Comunidade caiçara, Praia do Sono.

Keywords:

Social Ecology,

Qualitative research,

Social Technology,

Caiçara Community,

Praia do Sono.

\begin{abstract}
RE S U M O
O presente estudo buscou identificar a história e a cultura da Comunidade caiçara da Praia do Sono, localizada em Paraty (RJ), para atuar em projeto com participação social através da implementação de uma tecnologia social de saneamento ecológico. Para conhecimento da cultura daquele território, inicialmente foi realizada pesquisa bibliográfica a partir de dados secundários para levantamento do histórico de ocupação do território e melhor entendimento da formação da comunidade. A pesquisa qualitativa foi utilizada no uso de observação participante e condução de entrevistas semiestruturadas, ao final do projeto, para aprofundamento da abordagem psicossocial. As entrevistas buscaram explorar a relação da comunidade com a sua cultura e o movimento de preservar sua identidade e seu território e revelaram a importância de se conhecer as pessoas de uma localidade, suas trajetórias psicossociais e o tecido social para poder não só adaptar as metodologias, mas efetivamente incluir a cultura da comunidade no processo. Cabe ressaltar a relevância de se conduzir essas entrevistas com as lideranças comunitárias e os resistentes ativos ao projeto proposto já no início, para construir uma voz coletiva que realmente represente aquelas pessoas.
\end{abstract}

\section{A B S T R A C T}

The present study sought to identify the history and culture of the Caiçara community of Praia do Sono to act in a project with social participation through the implementation of a social technology of ecological sanitation. To get to know the culture of that territory, bibliographic research was initially carried out using secondary data to survey the history of occupation of the territory and better understanding of the formation of the community. Qualitative research was used to use participant observation and conduct semi-structured interviews, at the end of the project, to deepen the psychosocial approach. The interviews sought to explore the community's relationship with its culture and the movement to preserve its identity and its territory and revealed the importance of getting to know the people of a locality, their psychosocial trajectories and the social fabric in order to not only adapt the methodologies, but

\footnotetext{
1 Pesquisador Fiocruz. E-mail: gustavoxmartins@gmail.com.

2 Professora Titular da Universidade Federal do Rio de Janeiro (UFRJ). E-mail: taniabm@gmail.com.

${ }^{3}$ Mestranda na Universidade Federal do Rio de Janeiro. E-mail: carinemarrot@gmail.com.

${ }^{4}$ Professor aposentado - UNIGRANRIO. E-mail: mthiollent@gmail.com.
} 
effectively include community culture in the process. It is worth emphasizing the relevance of conducting these interviews with community leaders and those resistant to the proposed project early on, to build a collective voice that really represents those people.

\section{INTRODUÇÃO}

O presente artigo pretende contribuir com a discussão sobre como o entendimento do território, por meio de seu povo e cultura viabilizam o desenvolvimento de projetos e intervenções tecnológicas com engajamento social que têm por objetivo a melhoria das condições de vida locais. Como apontado por Maciel e D’Ávila Neto (1995), não é possível implementar ações de desenvolvimento e preservação do meio ambiente sem incluir as pessoas dessas localidades, suas culturas e práticas.

Logo, para se pensar numa ecosofia humana, cabe compreendermos as culturas e identidades dos diversos grupos (GUATTARI, 1990) com os quais se pretende interagir, a fim de construir tecnologias sociais inclusivas que provoquem pertencimento. Com essa perspectiva, Harvey (2011) demonstra que as paisagens são marcadas pelas maneiras de viver a partir dos distintos processos sociais e políticos. Assim, territórios que reduzem a entrada do capital conseguem manter a conservação ambiental e também um fortalecimento da sua identidade social. No caso das comunidades tradicionais, esse fortalecimento é crucial para garantir 0 bem viver.

A começar pelo conhecimento do histórico da comunidade podemos identificar como há violações de direitos sociais básicos no modelo de "desenvolvimento" capitalista hegemônico e como essas comunidades são oprimidas por ações, intervenções, amparadas pela lógica desse modelo de desenvolvimento, que mais fragiliza do que contribui com o fortalecimento de suas culturas (GALLO e NASCIMENTO, 2019). Essa pesquisa é um desdobramento da tese "Saneamento Ecológico: Uma Abordagem Integral de Pesquisa-ação aplicada na Comunidade Caiçara da Praia do Sono em Paraty", uma vez que, pôde-se compreender com a conclusão da pesquisa que o entendimento em profundidade da população e sua relação com a cultura é primordial para elaboração de projetos de intervenção que sejam sustentáveis e gerem pertencimento (MACHADO, 2019).

Com base no contexto da comunidade caiçara da Praia do Sono, no município de Paraty, estado do Rio de Janeiro (RJ), apresenta-se a conjuntura de mudanças, adaptações e convivência que os caiçaras têm sido sujeitados nas últimas décadas para garantir sua regularização fundiária, seus direitos de existir e sua luta por justiça social (MACHADO, 2019). De cunho psicossocial, objetivou-se a compreensão dos comunitários com sua cultura, sua realidade atual e demais atores que compõem tal realidade, a partir de entrevistas semiestruturadas, para compreender as melhores formas de se atuar em pesquisa-ação, respeitando as singularidades daquele território. 


\section{FUNDAMENTAÇÃO TEÓRICA}

Havia uma grande contradição na visão eurocêntrica da ciência e tecnologia, de que a ciência e a tecnologia de ponta considerada "certa" viria da região norte global para resolver condições adversas no sul. Logo, os próprios cientistas, muitas vezes buscaram tropicalizar e adaptar soluções consideradas "certas" a situações de precariedade locais, o que muitas vezes não funciona, especialmente por não considerar as pessoas, os territórios, as culturas e identidades, como Lianza e Addor (2005) apontam no campo da engenharia no Brasil.

Nesse sentido, a ecologia de saberes proposta por Santos (2007) aponta a epistemologia do Sul e confronta a monocultura da ciência moderna, porque se baseia no reconhecimento da pluralidade de conhecimentos heterogêneos e em interações sustentáveis e dinâmicas entre eles sem comprometer a sua autonomia. Assim, seu intuito é cruzar conhecimentos, utilizando as sabedorias de todos os envolvidos, sejam as acadêmicas, tradicionais e do território, valorizando além da técnica, também a cultura, a natureza, e 0 modo de viver de cada grupo (MACHADO, 2019).

Dessa forma, cabe repensar a forma de olhar para o desenvolvimento da tecnologia a partir de novos prismas, que repensem e que promovam desenvolvimento social (HENRIQUES et al., 2018). Quando se fala de desenvolvimento social, deve-se levar em conta os contextos locais e ampliar os quadros de referência, para efetivamente compreender quais as melhores tecnologias para determinado território.

Nesse caminho, a solidariedade técnica é definida como a responsabilidade recíproca através do diálogo com os diversos atores para inovações sociais e tecnológicas visando o desenvolvimento social e solidário. Assim, a engenharia precisa ter uma abordagem sociotécnica, incluindo a sociedade. As soluções devem ser criadas a partir das "senzalas", ampliando a qualidade de vida, num modelo de desenvolvimento contra-hegemônico Lianza e Addor (2005).

É com este viés crítico que Dagnino (2014) delineia o conceito de Tecnologia Social (TS) e a adequação sociotécnica como forma de operacionalizá-lo. Entendida mais como um processo, a TS deve privilegiar o envolvimento dos atores sociais e prever a construção de um conhecimento científico-tecnológico novo em contraposição às Tecnologias Convencionais. Assim, define-se o que é ou o que deveria ser a tecnologia social como aquela orientada ao mercado interno de massa, não discriminatória (patrão $x$ empregado), adaptada ao reduzido tamanho físico e financeiro, de modo a liberar este potencial (físico e financeiro) e a criatividade do produtor direto, a fim de viabilizar economicamente os empreendimentos autogestionários.

No entanto, o conceito e o desenvolvimento de tecnologias sociais necessitam se aproximar mais da realidade dos empreendimentos econômicos solidários, uma vez que é o público local que utilizará a 
tecnologia, portanto, com quem se deve dialogar sobre seus desejos, considerando suas limitações de capital, capacidade e necessidade produtiva (ADDOR e HENRIQUES, 2015).

É a partir desse cenário que Thiollent (2011) aponta a pesquisa-ação como um alicerce fundamental para construir projetos de inovação que tenham participação social. Logo, para se ter inovação tecnológica ligada a renovação dos valores da vida, gerando transformação social, é necessário focar no diálogo intersetorial e em metodologias participativas; para sistematizar a interação dos atores sociais (LIANZA e ADDOR, 2005).

Logo, as Tecnologias Sociais e a pesquisa-ação trazem possibilidades de interação sociotécnica para se construir intervenções a partir do prisma da solidariedade técnica. Santos (2007) explicita a relevância da Ecologia de Saberes, como a forma de valorizar todos os saberes, acadêmicos e tradicionais, para construção de tecnologias inclusivas em um território. A partir da valorização dos diversos saberes apresentados por Boaventura de Sousa Santos, Milton Santos (2001) argumenta em favor da resistência do território, apontando que há uma relação entre a localidade e a identidade das pessoas:

O território não é apenas o conjunto de sistemas naturais e de sistemas de coisas superpostas. 0 território tem que ser entendido como o território usado, não o território em si. O território usado é o chão mais a identidade. A identidade é o sentimento de pertencer àquilo que nos pertence. $O$ território é o fundamento do trabalho, o lugar da resistência, das trocas materiais e espirituais e do exercício da vida (SANTOS, 2001, p. 293).

Assim, a engenharia engajada aborda um novo panorama de desenvolvimento tecnológico, baseada na participação social, na desconstrução e reconstrução dos engenheiros, e na pesquisa-ação, para incluir as vozes e necessidades dos territórios e projetar tecnologias que possam fomentar a vida e não estritamente a acumulação de capital (KLEBA, 2017). É a partir desse prisma que Souza (2017) buscou o tensionamento entre a produção teórica acadêmica, que estabelece relações entre desenvolvimento local, cultura e participação, e os significados atribuídos à experiência em estudo pelos sujeitos sociais que estão vivenciando e liderando tal experiência.

Em seu estudo, é apresentada a relevância da gestão comunitária dos "saberes" e do "saber-fazer" das populações rurais para a construção da territorialidade como expressão cultural e social local. Logo, é ressaltada a relevância da inclusão das questões culturais para se gerar pertencimento e inclusão ao longo dos projetos: "a preservação das identidades étnicas, dos valores culturais e das práticas tradicionais de uso dos recursos aparece como uma oportunidade de uma gestão ambiental e do manejo sustentável dos recursos naturais em escala local" (Souza, 2017, p.119).

Nessa mesma abordagem, Simoni (2000) destaca que "é preciso ver para entender, vivenciar para conhecer e habitar o modo de vida, para poder se comunicar com certa comunidade". É a partir desse olhar e dos desafios encontrados no processo que se compreendeu a necessidade de realizar entrevistas 
semiestruturadas na pesquisa-ação de saneamento ecológico, para se ter um olhar mais aprofundado daquela cultura e assim, poder reorganizar as formas de atuação, para se ter maior participação e envolvimento, tanto dos comunitários, como dos atores locais e da própria equipe multidisciplinar.

Dado o cenário teórico e prático, o presente artigo apresenta a relevância de se compreender o histórico e as raízes de cada território, para além do que é posto nos momentos dialógicos de tomada de decisão por consenso, como reuniões coletivas.

\section{MÉTODO DE PESQUISA}

A pesquisa-ação realizada na comunidade caiçara da Praia do Sono foi definida por necessidade das comunidades tradicionais identificada pelo Fórum de Comunidades Tradicionais de Angra dos Reis, Paraty e Ubatuba (FCT) com a participação da Fiocruz, em 2013. Assim, antes da pesquisa qualitativa no campo de estudo, diversas ações de intervenção quanto ao saneamento ecológico foram estruturadas junto aos atores locais. A seguir apresentamos esse caminho prévio metodológico, que embasou a pesquisa qualitativa realizada a partir de entrevistas semiestruturadas em 2018.

\subsection{0 caminho prévio metodológico da pesquisa-ação conduzida no território}

Antes do início do projeto de saneamento ecológico, em agosto de 2013 foram realizadas visitas técnicas participativas para construir um diagnóstico em conjunto com a comunidade. $O$ intuito foi de além de gerar pertencimento e participação no projeto, conhecer as inter-relações ambientais e sociais e modo de viver dos caiçaras em seu território.

Ao longo de 2013 e 2014 foi construído o mapa falado, que tinha por objetivo compreender a visão da comunidade sobre o saneamento. Ao longo da pesquisa-ação, de julho de 2014 a dezembro de 2018, foram realizadas várias reuniões com a comunidade e com os atores locais, inclusive com condução de inquérito sanitário, para se conhecer as reais condições da comunidade, sempre em conjunto, para que ela mesma trouxesse sua visão das necessidades.

A pesquisa-ação foi conduzida a partir dos seguintes ciclos não lineares: a) revisão bibliográfica; b) conhecimento de experiências práticas em outros locais; c) construção de propostas/soluções e discussão coletiva a partir de equipe multidisciplinar; d) seminários de apresentação e discussão das possibilidades de tecnologias com a comunidade e os diversos atores locais; e) implementação das ações coletivamente; f) discussão semanal/quinzenal com avaliação dos resultados por equipe multidisciplinar composta de acadêmicos, técnicos e comunitários; g) rodas de conversa e seminários para apresentação dos resultados; 
h) reconhecimento e redesenho dos projetos e soluções a partir dos diversos olhares; i) reconhecimento do que foi feito, dos desafios e das oportunidades por meio do diálogo em reuniões sistematizadas com os diversos atores locais, e j) condução de entrevistas semiestruturadas (MACHADO, 2019).

Ao longo do processo foram contratados construtores da própria comunidade como mobilizadores sociais para aprenderem na prática e foi construído inicialmente módulo de saneamento ecológico na escola como projeto piloto, que consistiu em um tanque de evapotranspiração. Após discussão e definição com a comunidade, foram construídos módulos de saneamento ecológico em 9 casas da comunidade e na associação de moradores, sempre fomentando a participação da comunidade e dos atores locais (MACHADO, 2019).

\subsection{A metodologia usada na pesquisa qualitativa}

Para embasar a pesquisa-ação em saneamento ecológico na comunidade caiçara da Praia do Sono, em Paraty (RJ), fez-se necessário estruturar uma metodologia de análise qualitativa, que pudesse abranger a diversidade, mas também garantir uma boa coleta de dados. Thiollent (2011) aponta como principais técnicas as entrevistas individuais e/ou coletivas, questionários convencionais, análise de documentos já elaborados e técnicas antropológicas como observação participante, diários de campo e histórias de vida.

Para conhecimento da cultura da comunidade, inicialmente foi realizada pesquisa bibliográfica a partir de dados secundários para levantamento do histórico de ocupação do território e melhor entendimento da formação da comunidade tradicional caiçara. A observação participante foi uma das técnicas utilizadas, consistindo na observação direta no campo juntamente com a condução de entrevistas semiestruturadas para aprofundamento da abordagem psicossocial.

A condução das entrevistas estimulou a análise e a busca pela compreensão das subjetividades inerentes aos indivíduos, organizações, comunidade e às relações sociais que se dão entre eles (MINAYO, 1993). Para isso, foi feito roteiro de entrevistas para se conhecer a relação da comunidade com sua cultura, a relação simbólica com a água e o saneamento na comunidade, percepções de sustentabilidade e participação social (MACHADO, 2019). Ou seja, o recorte utilizado buscou explorar a relação da comunidade com a sua cultura e o movimento de preservar sua identidade e seu território.

O projeto de saneamento teve início concretamente em julho de 2014 e as entrevistas semiestruturadas foram realizadas entre junho e julho de 2018, ao final do projeto, com o intuito de compreender com maior profundidade as dinâmicas do tecido social construído nas interações coletivas. Foram realizadas nove entrevistas semiestruturadas para comparar as diversas visões da comunidade e dos atores locais envolvidos no processo. As entrevistas foram transcritas e posteriormente classificadas, por 
análise interpretativa. Como os dados foram obtidos por confidencialidade, os mesmos serão apresentados com pseudônimos, para evitar a exposição dos entrevistados (MACHADO, 2019).

Por tratar-se de pesquisa envolvendo seres humanos e ser realizada em Unidade de Conservação, o projeto de pesquisa foi submetido, avaliado e teve parecer favorável do Comitê de Ética em Pesquisa da Escola Nacional de Saúde Pública (CEP/ENSP) com número de registro 1.527 .081 e a pesquisa-ação na Comunidade Caiçara da Praia do Sono foi devidamente autorizada pelo Instituto Estadual do Ambiente (INEA), com autorização para pesquisa científica em unidade de conservação (número 044/14).

\section{RESULTADOS DA PESQUISA}

O território abrangido de Paraty (RJ) e da comunidade caiçara da Praia do Sono, assim como os conceitos de caiçaras e comunidades tradicionais foram compreendidos previamente e sistematizados.
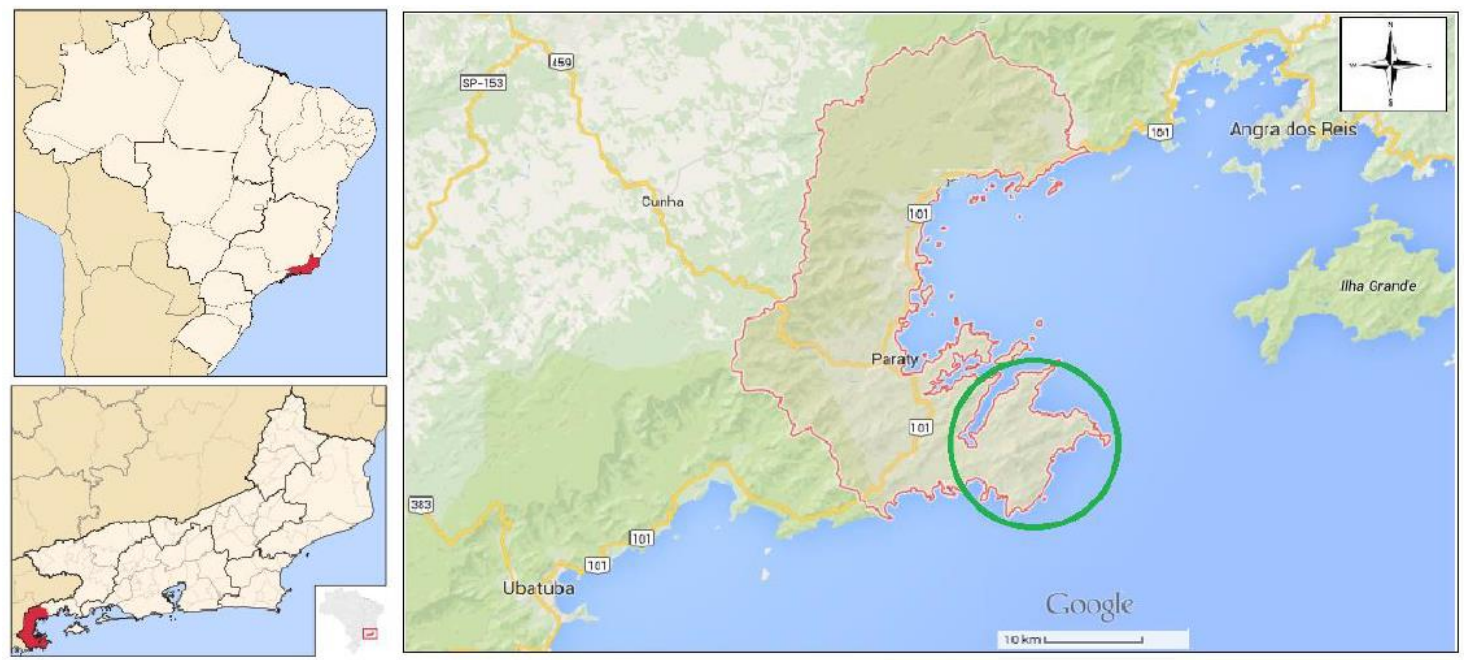

Figura 1 - Mapa com a localização da Península da Juatinga (RJ). Fonte: MACHADO, 2019.

As entrevistas semiestruturadas ratificaram as informações da revisão bibliográfica, de acordo com as classificações. Primeiro apresentamos os resultados do referencial teórico e posteriormente a discussão das entrevistas. Foi possível classificar o conteúdo em três aspectos da cultura caiçara: i) resistência pela sobrevivência, ii) mudança no senso de coletividade; e iii) preservação da cultura e relação com a natureza, os quais são apresentados na análise e discussão de resultados. A seguir são apresentados os resultados da revisão bibliográfica do território. 


\subsection{0 território}

A cidade de Paraty, no estado do Rio de Janeiro, uma das mais antigas do Brasil, reúne excepcional riqueza patrimonial, natural e cultural. As comunidades tradicionais de quilombolas, caiçaras e indígenas, que há muitas gerações ocupam o espaço e fazem a gestão dos recursos naturais de um modo particular, conservam esses habitats mantendo sua diversidade ambiental, cultural e social (DIAS e SEIXAS, 2017).

Em seus primórdios, Paraty era um porto seguro que se localizava na rota do comércio entre o Rio de Janeiro e as vilas vicentinas. A partir do século XVII, com a consolidação da era do ouro, Paraty se firmou como rota de passagem, provisionando alimentos e escravos para as Minas Gerais. Com a ferrovia, Paraty perdeu sua posição estratégica e assim, consolidou-se um modo de vida baseado em baixas trocas comerciais, diversificando a agricultura e fortalecendo a pesca (FRANCESCO, 2010).

A chegada dos "paulistas" alterou consideravelmente as posses de terras na região, muito em função da estrada Rio-Santos (CAVALIERI, 2003), que foi construída para interligar vários trechos litorâneos considerados isolados. Roças, mangues e rios gradativamente foram passando a ser propriedade privada e, 0 modo de vida que anteriormente era caracterizado pela subsistência, transformou-se em um modo de vida desigual e dependente (MONTEIRO, 2015). Grileiros muitas vezes acompanhados de capangas armados iniciaram agressivo e "violento processo de aquisição das terras" das populações tradicionais que, "devido à inexistência de propriedade legal, muitas vezes foram expulsos" (ADAMS, 2002, p.7), através de invasões, despejos e cobranças indevidas de documentos de arrendamento ou de parceria.

A abertura da estrada abriu espaço para um turismo que mudou vertiginosamente as formas de subsistência, resistência e relacionamento dessas populações, sendo sua inauguração o marco do início da fase turística da região (GUANZIROLLI, 1983). A partir da valorização do território, a especulação imobiliária definiu uma nova configuração, com a construção de condomínios fechados, com áreas privativas, localizados nas áreas mais valorizadas, entre o mar e a rodovia, gerando restrição no acesso às vias de acesso para as praias e a expulsão das populações tradicionais, às vezes à força, promovendo uma desestruturação da identidade desses povos e exclusão social (CORRÊA, 2008).

\subsection{As populações tradicionais}

As populações tradicionais são aquelas que, para proteger os ambientes em que vivem, se responsabilizam pelo controle dos recursos naturais (ALMEIDA e CUNHA, 2009). Trata-se de uma categoria social que define sujeitos com base em suas práticas, que se mobiliza em defesa de territórios marcados por modos de vida e histórico de ocupação diferenciados. Com esta compreensão, o principal atributo das 
populações tradicionais é a construção de um modo de vida alicerçado na relação de simbiose entre a natureza, seus ciclos e os recursos naturais (ARRUDA e DIEGUES, 2001).

O Decreto $n^{\circ} 6.040$ de 07 de fevereiro de 2007, instituiu a Política Nacional de Desenvolvimento Sustentável dos Povos e Comunidades Tradicionais e deliberou essas populações como grupos culturalmente diferenciados, que possuem formas próprias de organização social, utilizando conhecimentos, inovações e práticas gerados e transmitidos pela tradição (BRASIL, 2007). Assim, as comunidades tradicionais tiveram maior respaldo para se organizarem a partir do decreto.

Localizados em um território de exclusão social, as comunidades tradicionais da região de Angra dos Reis, Paraty e Ubatuba, perceberam que somente a luta social em conjunto ganharia mais força no sentido da conquista de direitos e assim, já lutavam por suas demandas de forma unificada, antes de 2006. Todavia, a partir deste decreto que pode se consolidar o Fórum de Comunidades Tradicionais de Angra dos Reis, Paraty e Ubatuba (FCT), que é um movimento social formado por lideranças de comunidades quilombolas, indígenas e caiçaras, criado exatamente para endereçar questões similares que esses povos passam (SOUZA, 2017).

Dentro do FCT, os caiçaras são as comunidades tradicionais mais desfavorecidas pelas dificuldades de reconhecimento de seus direitos e pela falta de regularização fundiária (MIGUELETO, 2011). Por habitarem a costa, no território entre mar e rodovia, passaram por muitas expropriações de suas terras. Assim, o lócus de recorte deste artigo, foi uma comunidade caiçara - a da Praia do Sono, localizada no município de Paraty, estado do Rio de Janeiro.

A determinação desta comunidade deve-se ao planejamento participativo interno, em que o FCT definiu que a pesquisa-ação de saneamento ecológico junto a Fiocruz ocorreria nas comunidades caiçaras, mais especificamente na Comunidade caiçara da Praia do Sono (GALLO et al., 2016). Logo, este estudo focou em uma compreensão qualitativa para compreender as particularidades dessa comunidade, baseada na sua história e cultura.

\subsection{Os caiçaras}

Os caiçaras são uma população constituída da miscigenação entre indígenas das tribos Tupi, como os Tupinambás, Tamoios e Tupiniquins, europeus portugueses, piratas e escravos (MUSSOLINI, 1980). A conformação dos seus povoados se caracterizava por grupamentos desordenados, em que as casas eram isoladas umas das outras e ficavam escondidas entre a vegetação e abrigadas do vento da praia. Também é importante ressaltar que a cada praia o grupamento caiçara é distinto, com características únicas (ADAMS, 2000), sendo assim uma população heterogênea, baseada na história e nas inter-relações de cada localidade, apesar das semelhanças culturais. 
Atualmente, a cultura caiçara continua sendo bastante relacionada à pesca, por sua importância econômica e social. Dentre os seus saberes também podem ser relatados a agricultura de roça, conhecimentos sobre o clima e geografia local, sobre o mar e as espécies de peixes e diferentes técnicas de pesca, festas e músicas, artesanato e construção de casas e canoas. As principais tecnologias caiçaras que foram documentadas são: pau a pique, telhado de sapê, farinha de mandioca, esteira de taboa, balaio, canoa caiçara e remo, arrasto de praia e o cerco flutuante (SOARES, GIACOMO e PEREIRA, 2016). É importante frisar que, assim como as demais culturas, a cultura caiçara também vai se modificando ao longo do tempo. Desde seu início, a partir da miscigenação e o contato com culturas externas, os caiçaras têm se reinventado e incorporado novas tecnologias, como por exemplo, a forma de salgar os peixes que permanece como parte da cultura.

Diegues $(2005$, p. 29) ressalta que "caiçaras (...) raramente aparecem nos arquivos e documentos históricos. É como se eles nunca tivessem existido", o que deixa clara a exclusão social dessas comunidades tradicionais desde a construção dos registros históricos. Ainda, em algumas referências bibliográficas, 0 termo caiçara está associado a preguiçoso e indolente, como "bons selvagens". Documentos recentes de criação de áreas protegidas em territórios caiçaras muitas vezes ignoram as comunidades ou as apresentam como pessoas que estão imersas na natureza, como se não precisassem ter direitos a serem atendidos - 0 que revela uma forma de manter a conservação ambiental através da expulsão dessas comunidades do seu entorno costeiro. Assim, os caiçaras além de fazerem parte das comunidades tradicionais, representam uma minoria marginalizada, muitas vezes não considerada socialmente (DIEGUES, 2005).

As comunidades caiçaras ficaram em voga no final da década de 1970 em virtude do avanço da especulação imobiliária, a chegada do turismo de massa e a implantação de unidades de conservação (UC) (DIEGUES, 2005), devido às adversidades que enfrentaram e ao contato com as pessoas de fora. Assim, muitas mudanças têm ocorrido nos seus hábitos e até mesmo com certa substituição de atividades, e abandono de certas práticas tradicionais, entretanto, em períodos de estagnação econômica as atividades de subsistência são retomadas (ADAMS, 2000). A pesca e o roçado foram prioritários para subsistência enquanto houve isolamento físico, no entanto continuam nos hábitos, mesmo que minoritariamente.

Os ranchos de pesca muitas vezes mudam, sendo transformados em bares ou quiosques para atender ao turismo. É fácil perceber as mudanças visíveis e materiais nos hábitos caiçaras, contudo é necessário um olhar mais atento para compreender que há uma manutenção da cultura e dos hábitos familiares:

É mais evidente perceber a alteração e a descaracterização ocorridas com a chegada do turismo, contudo, notar as permanências que se revelam requer uma análise atenta. Uma delas, por exemplo, o modo de vida tradicional camponês que pode ser notado no trabalho familiar que ainda ocorre, nas comunidades estudadas, com a coordenação feminina. (CAVALIERI, 2003, p. 245). 
Assim, uma das maiores fraturas do turismo não é a mudança da cultura, mas a relação do caiçara com a terra, que a partir de agora está associada a um valor de mercado, de acordo com a localização (CAVALIERI, 2003). Dessa forma, os mecanismos hegemônicos do capitalismo começam a gerar uma desigualdade social entre caiçaras que moram próximos ao mar e os que moram no sertão, sem tantos atrativos ao turismo.

Neste cenário é importante abordar a criação de áreas protegidas como Unidades de Conservação (UCs), que surgiram como uma resposta ao forte desenvolvimento urbano-industrial, visando proteger a biodiversidade no mundo todo. No Brasil o contexto das UCs é deficiente pelo fato de não terem tido implantação e estruturação adequados (DIOS, 2005), tendo conflitos desde as primeiras definições de áreas protegidas (BRITO, 2008).

A comunidade caiçara da Praia do Sono possui sobreposição de duas UCs. A Área de Proteção Ambiental (APA) do Cairuçu e a Reserva Estadual Ecológica da Juatinga (REJ/INEA), onde residem diversas comunidades. Pela sobreposição de responsabilidades, a gestão do território se apresenta fragmentada, pois as competências dos órgãos muitas vezes não se complementam com responsabilidades claras (CAVALIERI, 2003). Inicialmente, tais órgãos não se associaram às populações locais em prol da conservação ambiental, impondo restrições às práticas tradicionais, sem diálogo para compreensão das questões ambientais (SOUZA e LOUREIRO, 2015). Este fato foi bastante explorado e aprofundado com os caiçaras ao longo das entrevistas.

Em estudo realizado em 2011, havia aproximadamente 314 moradores nativos (177 homens e 137 mulheres) na comunidade caiçara da Praia do Sono. A principal atividade econômica de seus moradores é 0 trabalho com turismo, em restaurantes e bares, campings, pousadas e aluguel de casas de veraneio, seguido do transporte em botes e pesca artesanal. O roçado atualmente é minimamente realizado para subsistência e não para comércio, devido às práticas de cerceamento ambiental, praticado pelas UCs. A Praia do Sono tem energia elétrica desde 2009 e não há serviços de transporte público. Todo o transporte é feito em barcos e botes de particulares ou através de trilhas. Quando o mar está virado, ou seja, quando a maré está instável, revolta, com fortes ventos e ondulações, não há possibilidade de transporte por botes e apenas há trilha, que deve ser feita a pé e que passa por dentro de um condomínio privado (INEA, 2011).

As principais questões enfrentadas pelos moradores da Praia do Sono são: 1) o constrangimento de ter que passar pelo Condomínio Laranjeiras para ir e vir; 2) a regularização fundiária, tema bastante delicado; 3) a confusão gerada na instituição da Reserva Ecológica, que acabou criminalizando alguns hábitos caiçaras e portanto, afetando muito sua cultura (CAVALIERI, 2003). 
Ainda conforme a autora, as ações violentas para a expulsão dos moradores foram se modificando e tiveram requintes legais, como os contratos de comodato, que são até hoje uma grande ameaça a permanência das comunidades tradicionais em seus territórios.

Pelo frágil sistema educacional nesses locais, a maioria da comunidade era iletrada e acostumada a acreditar na palavra do outro, um código de costume caiçara. Aproveitando-se disso, muitos grileiros fizeram contratos de comodato, no qual os comunitários colocavam suas digitais no documento reconhecendo que residiam temporariamente, ou seja, "de favor" na expressão habitual, naquelas terras e que o proprietário permitia a habitação dos mesmos, podendo retirar essa autorização quando quisesse.

No caso da Praia do Sono, Gibrail, um dos maiores grileiros da região, passou a ter atitudes violentas, se imbuindo da "polícia" e da lei, para demolir suas casas (CAVALIERI, 2003), como relatado abaixo:

Gibrail usou de todos os expedientes que podia para ver os caiçaras fora das terras do Sono, começou impedindo o acesso à estrada, soltando búfalos e zebus nas plantações e até mesmo na Vila e, ainda, denunciando caiçaras como comunistas, o que resultou em prisão e processo - já que eram os anos do governo da ditadura (ZUQUIM, 2002, p. 175).

O livro "Genocídio dos Caiçaras" (SIQUEIRA, 1984) relata com detalhes o processo de luta, em que casas foram demolidas e muitos foram expulsos, indo para as periferias de Paraty. A permanência dos moradores que resistiram foi garantida com instauração de uma ação judicial, que se mantém até hoje (FRANCESCO, 2010). Na época da ação discriminatória, as mulheres da Praia do Sono expulsaram o grileiro que não voltou mais à comunidade.

Cabe retratar outro desafio que a comunidade da Praia do Sono tem vivenciado desde a década de 70 , com a construção do condomínio Laranjeiras. Como não há acesso direto dessa parte da orla, entre o condomínio e as estradas, os caiçaras têm que se submeter a processos rígidos de controle e só podem acessar o cais com a presença do grupo de segurança do condomínio, que os levam em veículo particular. Os caiçaras têm, portanto, fluxos de ir e vir cerceados (CAVALIERI, 2003). 


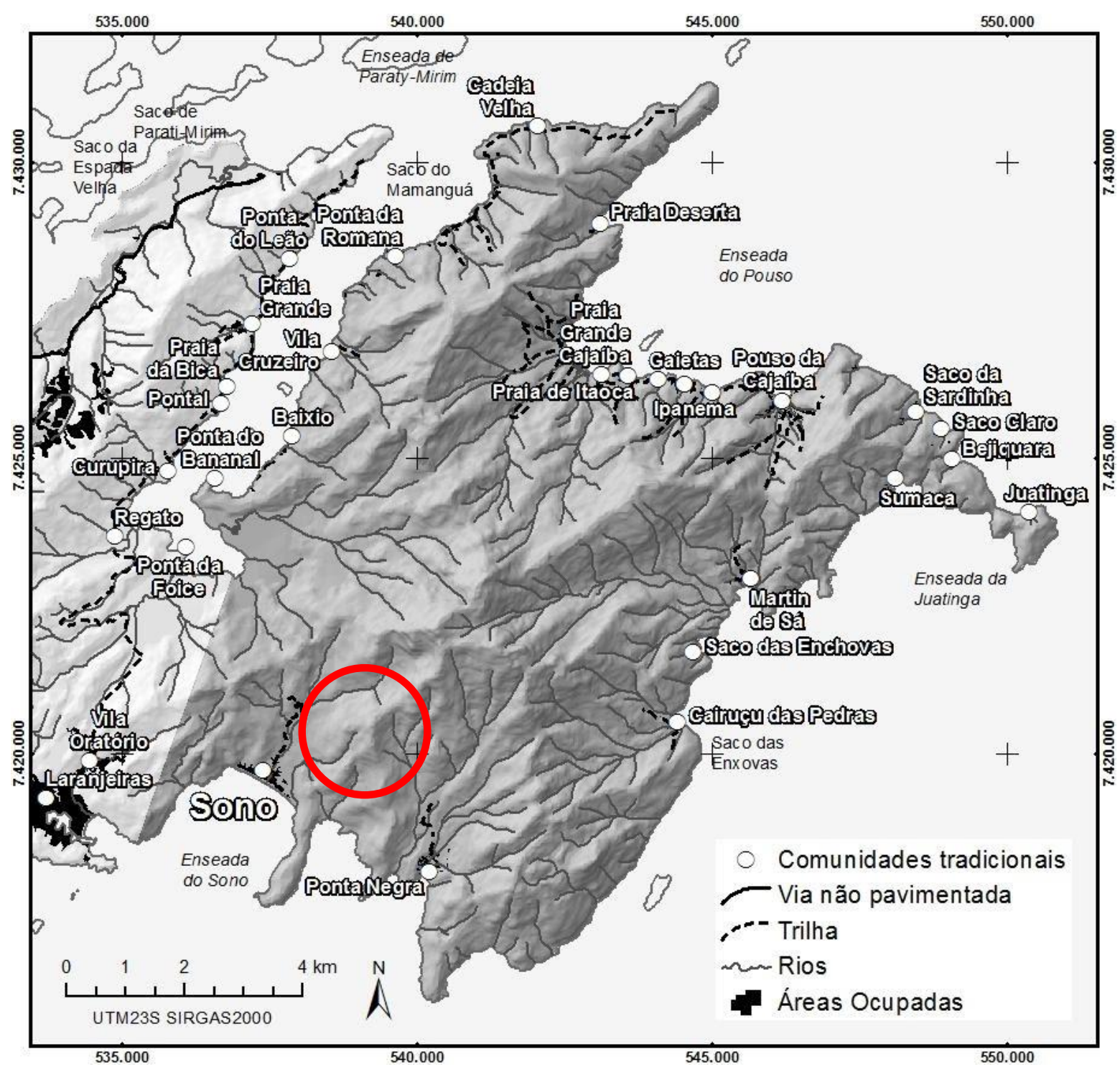

Figura 2 - Mapa dos núcleos e comunidades da Reserva Ecológica da Juatinga (REJ). 0 círculo representa a localização da Comunidade Caiçara da Praia do Sono, dentro da REJ.

Fonte: MACHADO, 2019.

A partir desse contexto, os caiçaras se mantém na disputa por seu território com muitos contrastes, como pode ser percebido na análise e discussão dos resultados.

\section{ANÁLISE E DISCUSSÃO DE RESULTADOS}

As entrevistas semiestruturadas ratificaram as informações teóricas, de acordo com as classificações aprofundadas abaixo: 


\subsection{Resistência pela sobrevivência}

Com relação à cultura da comunidade, pode-se observar que pelas diversas tentativas de expropriação de suas terras por grileiros, pelas restrições ambientais das UCs, que cercearam muitos dos seus hábitos, como por exemplo os roçados e a caça. Há uma resistência natural a projetos externos, para garantirem seu direito de permanecer no seu território.

É uma comunidade de resistência, devido a processos de luta, né, que teve todo o enfrentamento, que teve essa coisa do Gibrail, que era um grileiro de terra que tentou expulsar a comunidade. Depois disso, teve a unidade de conservação, que proibiu muita gente de plantar, de caçar, muita gente foi criminalizada por isso (Milena).

Em relação às UCs, os comunitários inicialmente imaginaram que as áreas de proteção ambiental iriam garantir seu bem viver no território. Contudo, as legislações cuidavam ambientalmente dos territórios, mas eram excludentes quanto às pessoas que habitavam esses locais, sua cultura e seu modo de viver. Assim, há uma postura de questionamento e de introversão com relação a projetos externos, que deve ser compreendida e aceita, por todas as experiências prévias da comunidade com atores locais. Atualmente, a resistência se traduz na dificuldade de relação com o Condomínio Laranjeiras:

Nós não temos uma passagem livre (...) que é por onde podemos, na emergência, sair através de um bote. Então é complicado. Já passei alguns problemas (...) e não poder chamar a ambulância pra ir lá pra dentro (Julia).

Portanto, o fortalecimento da comunidade para resistir no seu território trouxe uma grande desconfiança em atores externos, como é reconhecido pelos próprios caiçaras:

E aí toda essa resistência acabou trazendo nas pessoas, uma desconfiança, de qualquer um que chega lá. Pode levar projeto, pesquisa, pode ser prefeitura, (...) têm muita desconfiança de tudo (Milena).

\subsection{Mudança no senso de coletividade}

Em sua origem, a cultura comunitária apresentava uma vida centrada na subsistência, nas trocas comunitárias entre si, no roçado para alimentação e na pesca. $O$ trabalho consistia num apoio de toda a família com participação das mulheres e dos homens em diferentes posições (SOARES, GIACOMO e PEREIRA, 2016). A comunidade antigamente tinha pouco dinheiro e um forte senso de comum, de cuidado dos espaços coletivos e de troca de subsistência dos alimentos (OSTROM, 2000), como relatado abaixo:

Então, não tinha essa ganância do dinheiro. (...) Para ganhar dinheiro, ou você pescava, vendia seu peixe, ou a farinha - eram as coisas que você tinha. Se trocava muito ali (Luiza). 
Como relatado ao longo desse artigo, muitos dos hábitos relacionados com sua identidade e com a cultura caiçara foram alterados por conta de cerceamentos ambientais, como a perda das casas de farinha, pela perda dos roçados. Esse foi um campo fértil para a entrada do turismo predatório, que trouxe ganhos e subsistência financeira, mas que simultaneamente alterou as formas dos comunitários lidarem com o comum, com seus espaços coletivos. Os comunitários apresentaram a percepção de que o capitalismo e o turismo fomentam a competição e afastam as pessoas em suas relações interpessoais:

O capitalismo consegue injetar a desavença, né. Aquela coisa de fazer cerca, de fazer muro, de ter que competir com o próprio irmão de sangue inclusive (Pedro).

As mudanças nas relações a partir do acúmulo de capital aprofundaram uma desigualdade social, que começa a se manifestar na comunidade, uma vez que aqueles que moram mais próximos à praia têm contato direto com turistas e, portanto, mais possibilidades de ganhar dinheiro:

Porque quem tá lá pra cima da cachoeira muitas vezes não ganha nada, porque o turista não chega lá, não chega da forma que chega na praia, né. $E$ aí isso foi gerando uma desigualdade (Milena).

Há uma mudança no senso de coletividade da comunidade, constatada e discutida por todos os comunitários entrevistados. Como Ostrom (2000) aborda a Tragédia dos Comuns, com a entrada de recurso financeiro abundante por parte do turismo, a atuação comum ficou enfraquecida para novas ações:

Pra mim, nós éramos muito ricos. (...) as pessoas se uniam pra fazer a casa dos seus parentes, do seu amigo, onde se unia para pescar, para dividir o peixe, e então a dificuldade fazia com que as pessoas se unissem. Então hoje, que as coisas são fáceis, as pessoas estão cada uma por si (Luiza).

Entretanto, a observação participante nos trouxe a percepção de comportamentos diferentes dos expostos, pois: ao mesmo tempo em que escutamos que não se recebe mais peixe gratuitamente, verificamos em pesquisa de campo comunitários recebendo peixes por ajudar, ou seja, em troca da colaboração entre eles, e às vezes apenas por amizade (mesmo que fossem destinados à venda). Mesmo com todas as mudanças culturais, existe uma persistência do cuidado comum na comunidade caiçara da Praia do Sono.

\subsection{Preservação da cultura e relação com a natureza}

Não obstante todas as mudanças, o caiçara ainda mantém uma relação de solidariedade, a defesa de seu território, a manutenção de sua cultura:

A gente ainda mantém uma relação muito grande com a cultura, com a alma desse lugar, né, com a natureza... porque nós fazemos parte dela (...) a gente ainda consegue manter 
um pouco as nossas tradições (...) que isso gradativamente vai passando de geração pra geração (Pedro).

Esta fala retrata e apresenta, na essência, a relação dos comunitários da Praia do Sono com seu território. É importante frisar que a relação com a natureza e sua preservação é um traço forte da tradição caiçara e que os entrevistados reconhecem que estão em processo constante de fortalecimento e autopreservação, que existe a manutenção de muitos hábitos da cultura caiçara e outros estão sendo adaptados com o que chega de fora. Mesmo com o turismo predatório, a cultura ainda permanece e é passada de geração para geração oralmente:

O caiçara, como um sujeito de direito do território, como um grupo social que se distingue da sociedade urbana industrial (...) a gente vê na molecada, inclusive, esse conhecimento tradicional da natureza vindo na veia, na ancestralidade deles (João).

A valorização da cultura local, as relações comunitárias e a ideia de associativismo estiveram presentes em todas as falas nas entrevistas com os comunitários e atores locais, trazendo novos ares de resistência e fortalecimento da identidade caiçara, que se reinventa a cada passo.

\section{CONSIDERAÇÕES FINAIS}

Ao longo da pesquisa qualitativa pode-se constatar que as consequentes ações hegemônicas oriundas do capitalismo desde a década de 50, através das ações dos grileiros de terras, passando pelas UCs, com cerceamento das atividades culturais dos caiçaras que os conectam com sua identidade e a relação com a natureza. Até os desafios atuais com a implantação do Condomínio Laranjeiras, demonstram a força do capital para promover a expropriação e expulsão das comunidades tradicionais de seus territórios.

Assim, a Comunidade Caiçara da Praia do Sono, com todo seu histórico de luta, representa um espelhamento do que muitas comunidades tradicionais vivenciaram na região e continuam a vivenciar, em feridas reeditadas, com constantes investidas do capital, gerando expropriação de direitos e violência social. Cabe ressaltar que as ferramentas utilizadas antes do início do projeto como o mapa falado, inquérito e diversas reuniões com a comunidade ao longo do processo foram realizadas para se compreender a cultura da comunidade e a melhor maneira de interagir em um projeto de pesquisa-ação em saneamento ecológico.

Contudo, a partir das entrevistas, feitas apenas na parte final do projeto de saneamento ecológico, pode-se compreender de maneira mais profunda e sensível a resistência oriunda das raízes culturais da comunidade. Muitas das posturas dos comunitários tais como a ausência de participação e demais desafios relacionais - tanto entre comunitários em si como entre comunitários e a equipe do projeto - vividos ao longo do processo poderiam ter sido mapeadas se entrevistas tivessem sido utilizadas também no início do projeto. 
Assim, pode-se compreender na condução das entrevistas a importância de se conhecer as pessoas de um território, suas trajetórias psicossociais e o tecido social que se manifesta de forma profunda e sensível, para poder não só adaptar as metodologias, mas efetivamente incluir a cultura de cada localidade no processo. Ainda, cabe ressaltar a relevância de se conduzir essas entrevistas com as lideranças comunitárias e os resistentes ativos ao projeto proposto já no início, para poder efetivamente envolver os atores e construir uma voz coletiva.

Ao se trabalhar com projetos de saneamento na área rural, é de suma importância o envolvimento das pessoas, seja na construção, na compreensão e na manutenção dos sistemas construídos. Por isso é necessária a contribuição dessas comunidades, atuando como protagonistas, a partir de uma ecologia de saberes e da participação social das mesmas. Ainda há um caminho extenso para construir ações que não sejam homogêneas e que efetivamente incluam as vozes, as histórias, e as reais necessidades dos indivíduos, sejam eles caiçaras, quilombolas ou indígenas. Nesse processo, o FCT, criado pelas próprias comunidades com o mote "preservar é resistir", traz ensinamentos primordiais de valorização e fortalecimento cultural para o bem viver.

\section{REFERÊNCIAS}

ADAMS, C. As Populações Caiçaras e o Mito do Bom Selvagem: a necessidade de uma nova abordagem interdisciplinar. Revista de Antropologia, São Paulo, v. 43, n 1, 2000.

ADAMS, C. Identidade Caiçara: exclusão histórica e sócio-ambiental. Atualidades em Etnobiologia e Etnoecologia. Palestras convidadas do IV Simpósio Brasileiro de Etnobiologia e Etnoecologia. Recife: Sociedade Brasileira de Etnobiologia e Etnoecologia, 2002.

ADDOR, F.; HENRIQUES, F. Tecnologia, participação e território: reflexões a partir da prática extensionista. Rio de Janeiro: Editora UFRJ, 2015. Disponível em: http://nides.ufrj.br/images//magens/programas/SOLTE C/Soltec_3Tecnologia_participacao_e_territorio_baixa Res.pdf Acesso em: 18 nov. 2019.

ALMEIDA, M.; CUNHA, M. Populações Tradicionais e Conservação Ambiental. In Cunha, M. Cultura com aspas e outros ensaios, São Paulo: Cosac Naify, 2009.

ARRUDA, R.; DIEGUES, A. Saberes tradicionais e biodiversidade no Brasil. Ministério do Meio Ambiente; São Paulo: USP, 2001.

BRASIL. Decreto n. ${ }^{\circ} 6.040$, de 7 de fevereiro de 2007. Institui a Política Nacional de Desenvolvimento
Sustentável dos Povos e Comunidades Tradicionais. Brasília, 2007.

BRITO, D. Conflitos em unidades de conservação. Pracs - Revista de Humanidades do Curso de Ciências Sociais. Macapá: Unifap, 2008.

CAVALIERI, L. A comunidade caiçara no processo de reclassificação da reserva ecológica da Juatinga. 2003. Dissertação (Mestrado em Geografia Humana) - Faculdade de Filosofia, Letras e Ciências Humanas, Universidade de São Paulo, São Paulo, 2003.

CORRÊA, R. Angra dos Reis: contribuição ao entendimento de uma pretensa vocação turística pensando o turismo a partir do território Angra dos Reis. São Paulo: Anais do IV Encontro Nacional De Grupos De Pesquisa, 2008.

DAGNINO, R. Tecnologia Social: contribuições conceituais e metodológicas. Campina Grande: EDUEPB, 2014. Disponível em: http://books.scielo.org/id/7hbdt/pdf/dagnino9788578793272.pdf Acesso em: 25 nov. 2019.

DIAS, A.; SEIXAS, C. Conservação Ambiental em Paraty, RJ: Desafios para se Colocar a Ciência em Prática. Biodiversidade brasileira: ICMBIO, 2017. 
DIEGUES, A. Enciclopédia Caiçara: História e Memória Caiçara, v.4. São Paulo: Editora HUCITEC-NUPAUBCEC/USP, 2005.

DIOS, C. Aplicabilidade da legislação ambiental na gestão das unidades de conservação: 0 caso do Parque Nacional da Restinga de Jurubatiba. 2005. Dissertação (Mestrado em Geografia) - Programa de Pós-Graduação de Geografia, Universidade Federal do Rio de Janeiro, Rio de Janeiro, 2005.

FRANCESCO, A. Território em disputa: o caso dos caiçaras da Cajaíba. 2010. Dissertação (mestrado em Antropologia) - Programa de Pós-Graduação em Antropologia Social, Universidade de Campinas, Campinas, 2010.

GALLO, E.; SETTI, A.; RUPRECHT, T.; SOBRINHO, F.; FINAMORE, P.; SHUBO, T.; MACHADO, G. Territorial Solutions, Governance and Climate Change: Ecological Sanitation at Praia do Sono, Paraty, Rio de Janeiro, Brazil. Climate Change Management 1ed.: Springer International Publishing, 2016.

GALLO, E.; NASCIMENTO, V. O Território Pulsa: territórios sustentáveis e saudáveis da Bocaina: soluções para a promoção da saúde e do desenvolvimento sustentável territorializados. $1 \mathrm{ed}$. Paraty: Fiocruz, 2019.

GUANZIROLLI, C. Contribuição e reflexão sobre 0 processo de produção de um espaço regional. 0 caso de Angra dos Reis. 1983. Dissertação (Mestrado em Geografia) - Programa de PósGraduação de Geografia, Universidade Federal do Rio de Janeiro, Rio de Janeiro, 1983.

GUATTARI, F. As Três Ecologias. Campinas: Papirus, 1990.

HARVEY, D. O enigma do capital: e as crises do capitalismo. São Paulo: Boitempo, 2011.

HENRIQUES, F.; ADDOR, F.; MALINA, A.; ALVEAR, C. Tecnologia para o desenvolvimento social: diálogos Nides-UFRJ. Marília: Lutas Anticapital, 2018. Disponível em: http://nides.ufrj.br/images//magens/programas/SOLTE C/Publicacoes/LivroComCapa_BaixaRes.pdf Acesso em: 8 nov. 2019.

INSTITUTO DO MEIO AMBIENTE - INEA. Definição de categoria de unidade de conservação da natureza para o espaço territorial constituído pela reserva ecológica da Juatinga e área estadual de lazer de Paraty Mirim. Reserva Ecológica da Juatinga, 2011.

KLEBA, J. Engenharia engajada - desafios de ensino e extensão. Revista Tecnologia e Sociedade, Curitiba, v. 13, n. 27, pp. 170-187, jan./abr, 2017. Disponivel em:

https://revistas.utfpr.edu.br/rts/article/viewFile/4905/33 47 Acesso em: 3 dez. 2019.
LIANZA, S.; ADDOR, F. Tecnologia e Desenvolvimento Social e Solidário. Porto Alegre: Editora UFRGS, 2005. Disponível em: http://nides.ufrj.br/images/Imagens/programas/SOLTE C/TecDesSocSol.pdf. Acesso em: 18 jan. 2020.

MACHADO, G. Saneamento Ecológico: Uma Abordagem Integral de Pesquisa-ação aplicada na Comunidade Caiçara da Praia do Sono em Paraty. 2019. Tese (Doutorado em Psicossociologia) EICOS/Programa em Psicossociologia de Comunidades e Ecologia Social, Instituto de Psicologia, Universidade do Rio de Janeiro, Rio de Janeiro, 2019.

MACIEL, T.; D'ÁVILA NETO, M. Comunidades e Participação: Desafios para a Pesquisa e Ação. 0 Caso do Pantanal.In: Maria Inácia D'Ávila. (Org.). Desenvolvimento Social: Desafios e Estratégias. Rio de Janeiro: Cátedra UNESCO de Desenvolvimento Durável - UFRJ/EICOS, pp. 228-243, 1995.

MIGUELETO, D. A encruzilhada do desenvolvimento. 2011. Tese (Doutorado em Ciências Sociais) Instituto de Ciências Humanas e Sociais, Universidade Federal Rural do Rio de Janeiro, Rio de Janeiro, 2011.

MINAYO, M. Pesquisa Social: Teoria, método e criatividade. Petrópolis: Vozes, 1993.

MONTEIRO, T. Ação política e afirmação territorial: turismo de base comunitária entre os caiçaras de São Gonçalo, Paraty, Rio de Janeiro. Espaço e Economia, 2015.

MUSSOLINI, G. Ensaios de Antropologia Indígena e Caiçara. Rio de Janeiro: Paz e Terra, 1980.

OSTROM, E. El gobierno de los bienes comunes: la evolución de las instituciones de acción colectiva. México: Universidad Nacional Autónoma de México, 2000.

SANTOS, B. Para além do pensamento abissal: das linhas globais a uma ecologia de saberes. Novos estudos - CEBRAP n.79, São Paulo, 2007.

SANTOS, M. Território e Sociedade. Entrevista com Milton Santos. 2. ed., São Paulo: Editora Fundação Perseu Abramo, 2001.

SIMONI, M. Engenharia de Produção da Exclusão Social. In: Thiollent, M., Araújo Filho, T. \& Soares, R.L.S. (Org.). Metodologia e Experiências em Projetos de Extensão. EdUFF, Niterói, 2000.

SIQUEIRA, P. Genocídio dos caiçaras. Massao Ohno São Paulo: Ismael Guarnelli Editores, 1984.

SOARES, T.; GIACOMO, M.; PEREIRA, M. (2016). Memórias e Práticas Caiçaras da Península da Juatinga. 1a. ed. Rio de Janeiro: Proext Cultura 2015 MEC.

SOUZA, L. Cultura, Identidade e Desenvolvimento Local: O" Me Conta" E O Médio Rio das Contas." 
Revista de Gestão Social e Ambiental 2017: 107-123, 2017.

SOUZA, V.; LOUREIRO, C. A educação formal enquanto estratégia de luta dos povos caiçaras da Península da Juatinga, Paraty/RJ. Cadernos de Educação1, UFPel: Pelotas, 2015.

SOUZA, V. Educação para permanecer no território: a luta dos povos tradicionais caiçaras da Península da Juatinga frente à expansão do capital em Paraty-RJ. 2017. Tese (doutorado em Psicossociologia) EICOS/ Programa em Psicossociologia de Comunidades e Ecologia Social, Instituto de Psicologia, Universidade do Rio de Janeiro, Rio de Janeiro, 2017.

THIOLLENT, M. Metodologia da pesquisa-ação.18. ed. São Paulo: Cortez, 2011.

ZUQUIM, M. Os Caminhos da Bocaina: uma Questão Agrária Ambiental. 2002. Tese (Doutorado em Arquitetura) - Faculdade de Arquitetura e Urbanismo, Universidade de São Paulo, São Paulo, 2002. 